\title{
Soybean plants expressing the Bacillus thuringiensis cry8-like gene show resistance to Holotrichia parallela
}

\author{
Di Qin ${ }^{1,2}$, Xiao-Yi Liu ${ }^{3}$, Cristina Miceli², Qi Zhang ${ }^{1}$ and Pi-wu Wang ${ }^{1 *}$
}

\begin{abstract}
Background: Cry8-like from Bacillus thuringiensis (Bt) encodes an insecticidal crystal (Cry) protein. Holotrichia parallela (Coleoptera: Scarabaeoidae), commonly known as the dark black chafer, is a troublesome pest of soybean (Glycine max). To test whether cry8-like can confer resistance against $H$. parallela to soybean, we introduced crys-like from the Bt strain HBF-18 into soybean cultivar Jinong 28.

Results: Quantitative reverse transcription-PCR analysis demonstrated that cry8-like was expressed most highly in soybean leaves. In addition, Southern blot assays revealed that one copy of the integrated fragment was present in the transformed plants. Eight independent cry8-like transgenic lines were subsequently fed on by H. parallela. Under $H$. parallela feeding stress, the survival rates of the non-transgenic plants were $92 \%$ lower than those of the transgenic plants. The mortality rate of $H$. parallela increased when the larvae fed on the roots of $T_{1}$ transgenic soybean plants. Moreover, the surviving larvae were deformed, and their growth was inhibited.

Conclusions: Collectively, our data suggest that transgenic soybean plants expressing the cry8-like gene are more resistant to $\mathrm{H}$. parallela than non-transgenic plants and that transgenic expression of the cry8-like gene may represent a promising strategy for engineering pest tolerance. The events generated in this study could thus be utilized in soybean breeding programs.
\end{abstract}

Keywords: Holotrichia parallela, Cry8-like, Bacillus thuringiensis endotoxin, Transgenic soybean

\section{Background}

Soybean (Glycine max L. Merr.) is a globally important crop species that is grown for its oil and protein; moreover, its seeds are used for human consumption, animal feed, and industrial raw materials [1]. Soybean is self-pollinated, and soybean seeds are rich in protein (38-40\%), in addition, soybean crops are utilized in crop rotations because of the ability of the plants to increase the amount of nitrate in the soil via symbiotic nitrogen fixation. However, soybean yields are severely affected by insects [2].

Holotrichia parallela (Coleoptera: Scarabaeoidea), commonly known as the dark black chafer, is one of the most important pests in agriculture and forestry in China [3]. H. parallela has a three-stage life cycle: the egg, larva and adult (Fig. 1). The larvae of $H$. parallela

\footnotetext{
*Correspondence: wangpiwu189@163.com

${ }^{1}$ Biotechnology Center of Jilin Agricultural University, Jilin Agricultural

University, Changchun 130118, People's Republic of China

Full list of author information is available at the end of the article
}

live in the soil and prefer to feed on plant roots during their two-year larval stage, and adult $H$. parallela insects feed on fresh leaves. $H$. parallela can cause considerable damage to soybean-from 10 to $30 \%$ yield losses in a typical year and up to $50 \%$ yield losses during severe infestations-and are responsible for \$1-2 billion in losses per year worldwide [4]. Currently, farmers apply insecticidal sprays for the control of these insect pests, however, because these larvae are soil dwelling, it is difficult to find a specific chemical product that can control these insects.

Conventional breeding approaches for insect resistance have limited success due to a lack of sources of resistance. As an alternative approach, genetic engineering using $c r y$ genes from the soil bacterium Bacillus thuringiensis (Bt) offers great potential for improving crop species $[5,6]$.

$B t$ genes encode a protoxin that is transformed to an active toxin via enzyme cleavage in the insect midgut [7]. Different types of cry genes have been used successfully to develop insect-resistant crop species. According to

(c) The Author(s). 2019 Open Access This article is distributed under the terms of the Creative Commons Attribution 4.0 International License (http://creativecommons.org/licenses/by/4.0/), which permits unrestricted use, distribution, and 


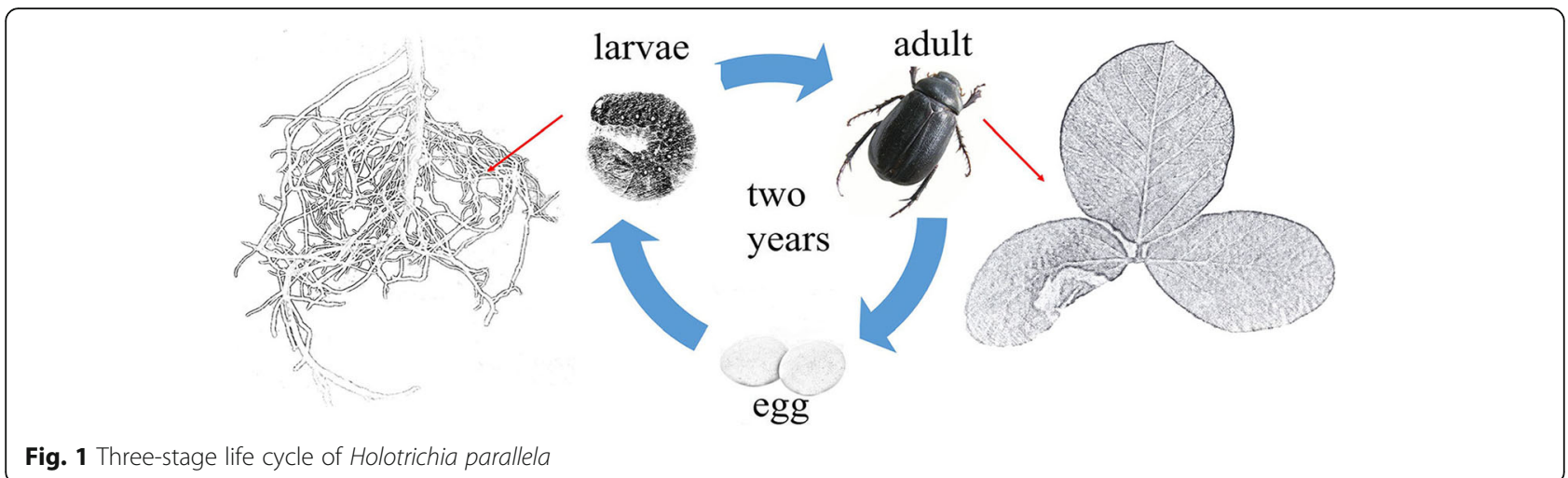

Fig. 1 Three-stage life cycle of Holotrichia parallela

insecticidal specificity, cry genes are mainly divided into 4 types including anti-Lepidoptera, anti-Diptera, antiColeoptera and anti-nematodes types. The $B t$ genes that provide resistance to Coleoptera include $\operatorname{cry} 3, \mathrm{cry} 4, \mathrm{cry} 7$, cry8, and cry23 [8]. Development of insect resistance via transgenesis with fused cry genes has been previously applied to protect cotton from damage to cotton bollworm insects [9]. A novel cry 8 gene exhibiting activity against the larvae of Holotrichia oblita and H. parallela was identified [10]. Furthermore, a chimeric cry8Ea1 gene flanked by MARs in transgenic peanut plants effectively controls $H$. parallela [11], but no studies have investigated transgenic soybean plants expressing cry8-like genes.

Therefore, in the present study, we used Agrobacteriummediated transformation to transform callus of the soybean cultivar Jinong 28. Jinong 28 has good agronomic characteristics but no resistance to $H$. parallela. We produced eight independent transgenic soybean lines expressing cry8like under the control of the CaMV 35S promoter. Insect feeding assays performed for a period of $96 \mathrm{~h}$ indicated effective protection of the soybean plants against $H$. parallela compared to the Jinong 28 control plants.

\section{Results}

\section{Production of transgenic soybean plants expressing the} cry8-like gene

The recombinant plasmid designated pCAMBIA3300cry8-like was introduced into Agrobacterium tumefaciens strain (Fig. 2a). The callus tissue used was originally derived from cotyledon-nodes of soybean (Fig. 2b). About 300 soybean cotyledon calluses were subjected to transformation. The putative transgenic embryos were grown with the addition.

of $50 \mathrm{mg} \cdot \mathrm{L}^{-1}$ kanamycin to select the transgenic plants. Approximately $3 \%$ of the stems (8 plants) developed on the kanamycin-selected cotyledons (Fig. 2c, d). 8 individual $\mathrm{T}_{0}$ plants (primary transformants) established in the green house that grew normally, flowered and set seeds (Fig. 2e). Since the transformants developed by the transformation strategy used could be chimeras in the $\mathrm{T}_{0}$ generation, screening of $\mathrm{T}_{1}$ generation plants for the identification of putative transformants was essential.

Detection of the cry8-like gene in the $T_{0} / T_{1}$ generations Southern blot assay was used to detect the presence and determine the copy number of the cry8-like gene in the selected eight putative transgenic lines. One copy of cry8like was detected in $\mathrm{T}_{0}$ generation of each line (Fig. 3a). $\mathrm{T}_{1}$ generation of transgenic lines were obtained by selfing and inheritance of cry8-like investigated by PCR and Southern blot assay. PCR analysis of 971 plants revealed a 3:1 segregation ratio indicating that the transgene was stably integrated in the soybean genome. Plants of the $T_{1}$ generation retained the single copy number of cry8-like insertion (Fig. 3b) and both in the $\mathrm{T}_{0}$ and $\mathrm{T}_{1}$ generations, each part of the transgene (cry8-like coding region, 35S promoter and Nos terminator) was detected in each selected line (Additional file 1: Fig. S1).

\section{Detection of the cry8-like expression in the transgenic lines}

Expression of cry8-like was studied by quantitative realtime PCR (qRT-PCR). The qRT-PCR results indicated that cry8-like was expressed in all organs (leaves, stems, and roots) of the transgenic soybean plants, with the highest expression level detected in the leaves (Fig. 4a). Two-way ANOVA (including all interactions and simple and main effects) was used to test for significant differences among the different organs and lines. The interaction between soybean lines and organs had a significant effect on the expression of cry8-like (Fig. 4b red), but the F-value of the interaction was small compared to that of the main effects. The results indicated that the simple and main effects of the lines and organs on cry8-like expression were more significant than the interaction effects. Two-way ANOVA revealed that there was a difference among the different cry8-like transgenic lines $(d f=7, F=435, P<0.001)$ and the different organs $(d f=2, F=8033, P<0.001) \quad$ (Fig. $4 \mathrm{~b})$. The expression 

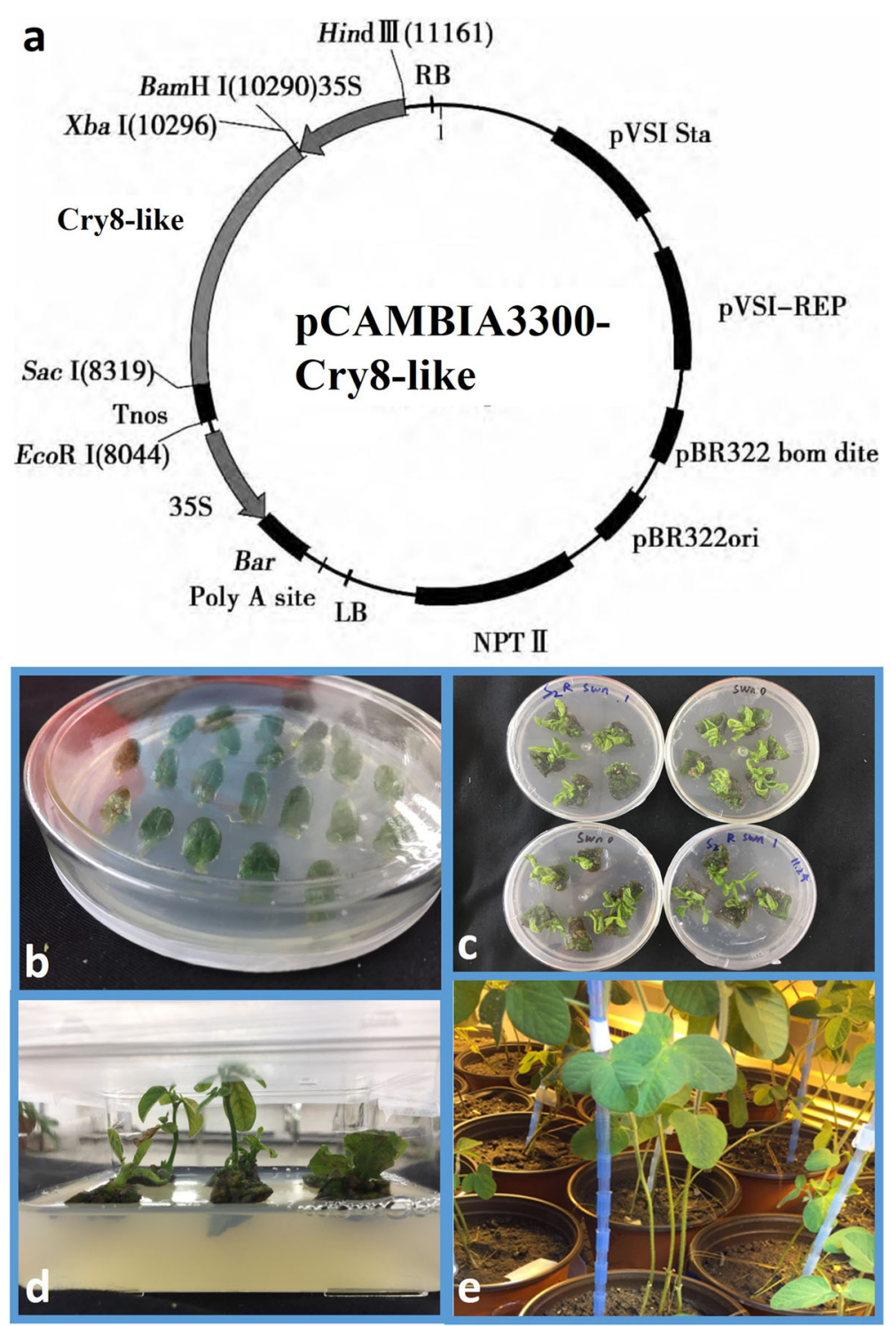

Fig. 2 Agrobacterium-mediated transformation of soybean. (a) Diagram of pCAMBIA3300-cry8-like used for transformation. (b) Soybean cotyledon nodes cultured on shoot-induction medium (c) and (d) Shoot development. (e) 3-month-old $T_{0}$ transgenic soybean plants grown under greenhouse conditions in soil

level of cry8-like in the eight lines followed the order

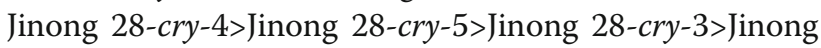
28 -cry-2 $\geq$ Jinong 28 -cry- $1 \geq$ Jinong 28 -cry-7 $\geq$ Jinong 28 cry-6>Jinong 28-cry-8 (Fig. 4c).

\section{Quantifying the level of cry endotoxin in the different organs}

An enzyme-linked immunosorbent assay (ELISA) was used to quantify the level of Cry endotoxin in the different organs (leaves, stems, and roots) of the transgenic soybean plants $\left(\mathrm{T}_{0} / \mathrm{T}_{1}\right.$ generation). Variable amounts of toxin accumulated in all transgenic plants and in all organs, whereas the nontransformed control plants did not show any accumulation of Cry endotoxin (Table 1). The Jinong 28-cry-4 transgenic plants showed the highest level of Cry protein accumulation (see Additional file 2: Table S1). The ELISA also revealed that high levels of endotoxin accumulated in the leaves and roots and that the lowest level of endotoxin accumulated in the stems (see Additional files 3: Table S2). The interaction between soybean lines and organs had a significant effect on the accumulation of BT protein (Table 2). Compared with that of the main effects, the F-value of the interaction is small, and the results indicate that the simple effects of the lines and organs on Bt toxin accumulation were more significant than were the main effects. 


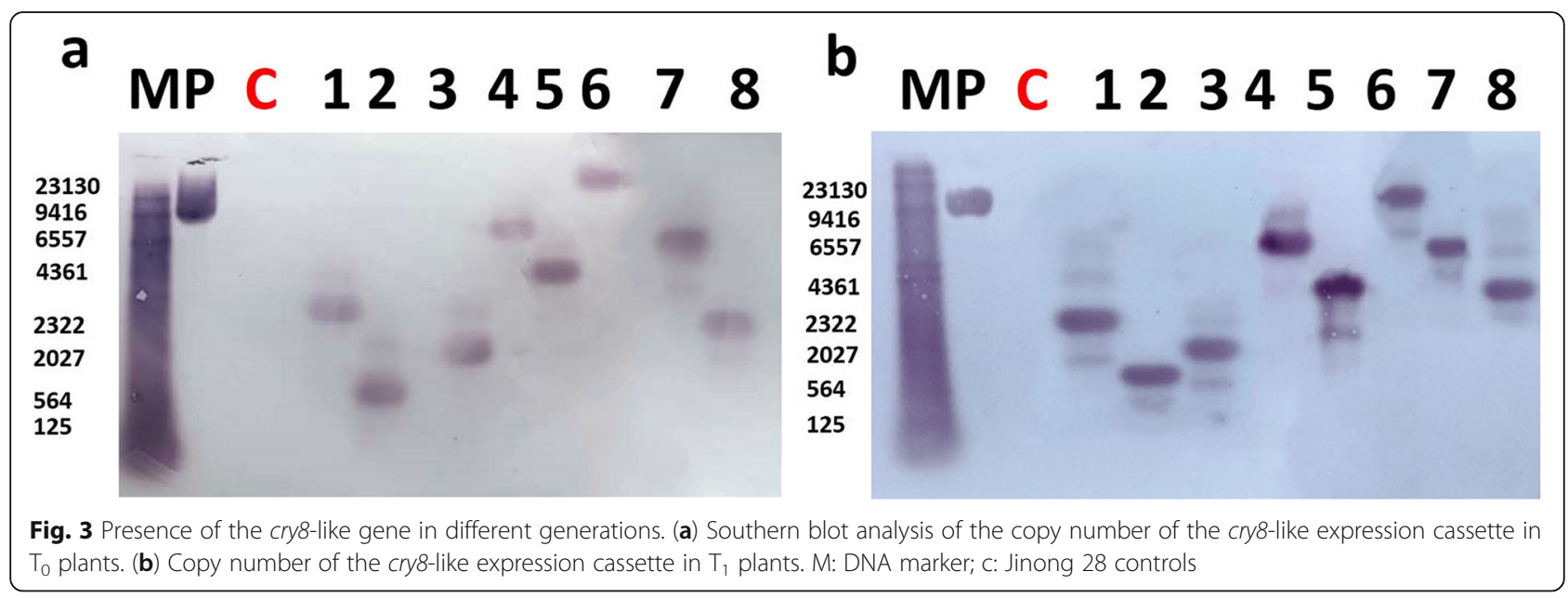

Tolerance of the cry8-like transgenic plants to $\mathrm{H}$. parallela After 4, 6 and 8 days of third-instar $H$. parallela larval feeding, extensive damage was incurred on the nontransgenic control plants (Fig. 5a). The eight independent cry8-like transgenic lines showed a high degree of plant survival after 8 days of feeding, and the maximum number of larvae were paralyzed after 4 days of feeding on these lines. The fresh weight of the transgenic lines was also greater than that of the controls, with the weight of the Jinong 28 controls being significantly lower (78\%) than that of the eight transgenic lines (Fig. 5b). We also investigated the effects of $H$. parallela feeding

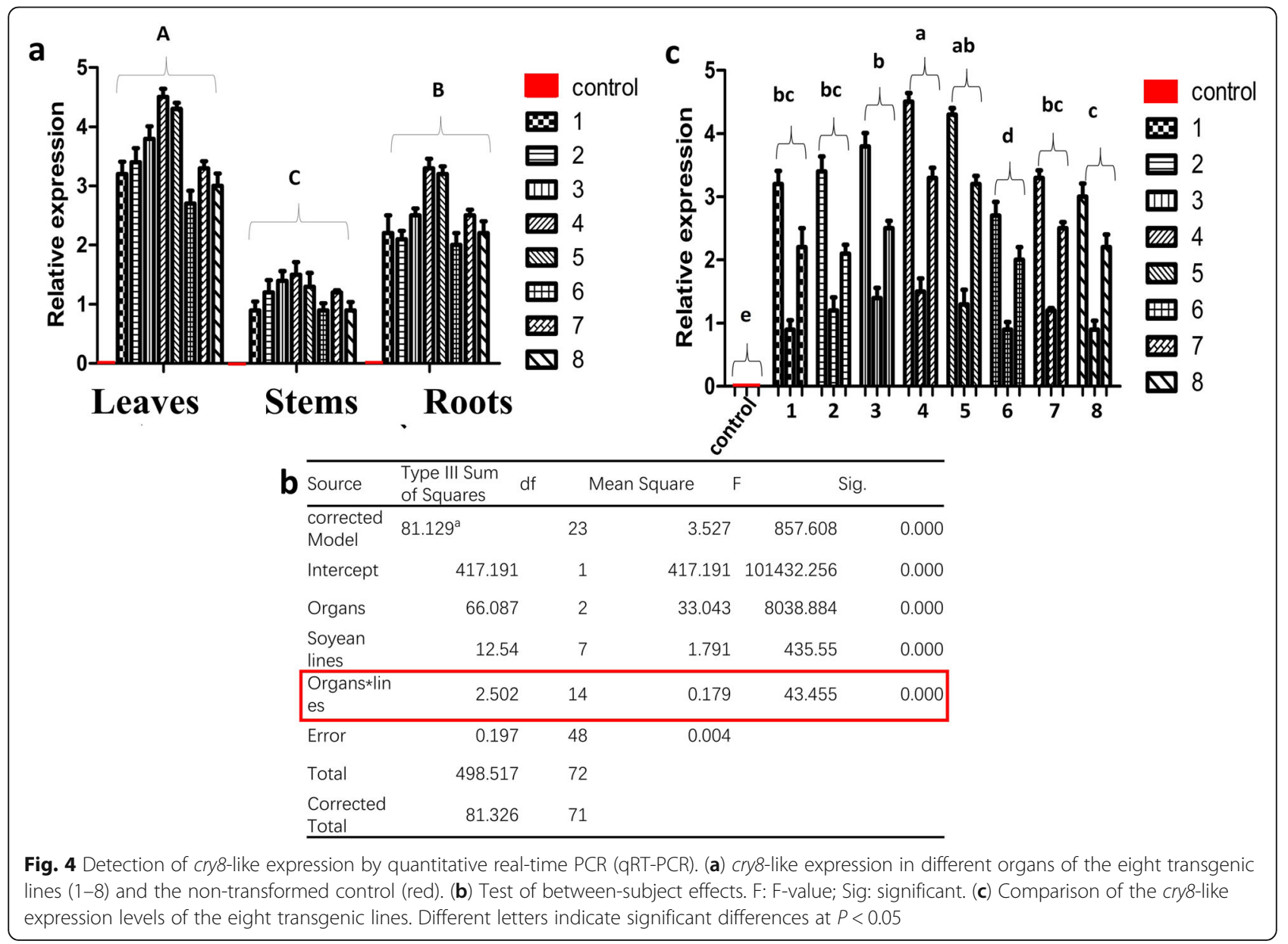


Table 1 Bt toxin accumulation in the transgenic plants

\begin{tabular}{|c|c|c|c|c|c|c|c|}
\hline $\begin{array}{l}\text { Plant line } \\
\left(T_{0}\right)\end{array}$ & $\begin{array}{l}\text { Bt toxin expression } \\
\left(\mathrm{ng} \cdot \mathrm{mg}^{-1}\right) \text { in leaves }\end{array}$ & $\begin{array}{l}\text { Bt toxin expression } \\
\left(\mathrm{ng} \cdot \mathrm{mg}^{-1}\right) \text { in stems }\end{array}$ & $\begin{array}{l}\text { Bt toxin expression } \\
\left(\mathrm{ng} \cdot \mathrm{mg}^{-1}\right) \text { in roots }\end{array}$ & $\begin{array}{l}\text { Plant line } \\
\left(\mathrm{T}_{1}\right)\end{array}$ & $\begin{array}{l}\text { Bt toxin expression } \\
\left(\mathrm{ng} \cdot \mathrm{mg}^{-1}\right) \text { in leaves }\end{array}$ & $\begin{array}{l}\text { Bt toxin expression } \\
\left(\mathrm{ng} \cdot \mathrm{mg}^{-1}\right) \text { in stems }\end{array}$ & $\begin{array}{l}\text { Bt toxin expression } \\
\left(\mathrm{ng} \cdot \mathrm{mg}^{-1}\right) \text { in roots } \\
\end{array}$ \\
\hline $\begin{array}{l}T_{0} / \\
\text { Jinong28 }\end{array}$ & - & - & - & $\begin{array}{l}\mathrm{T}_{1} / \\
\text { Jinong28 }\end{array}$ & - & - & - \\
\hline $\begin{array}{l}\text { Tol } \\
\text { Jinong28- } \\
\text { cry-1 }\end{array}$ & $12 \pm 1$ & $9 \pm 1$ & $10 \pm 2$ & $\begin{array}{l}\mathrm{T}_{1} / \\
\text { Jinong28- } \\
\text { cry-1 }\end{array}$ & $13 \pm 2$ & $11 \pm 1$ & $12 \pm 1$ \\
\hline $\begin{array}{l}T_{0} / \\
\text { Jinong28- } \\
\text { cry-2 }\end{array}$ & $15 \pm 2$ & $11 \pm 2$ & $14 \pm 2$ & $\begin{array}{l}\mathrm{T}_{1} / \\
\text { Jinong28- } \\
\text { cry-2 }\end{array}$ & $11 \pm 1$ & $8 \pm 1$ & $10 \pm 2$ \\
\hline $\begin{array}{l}\text { Tol } \\
\text { Jinong28- } \\
\text { cry-3 }\end{array}$ & $14 \pm 2$ & $11 \pm 1$ & $13 \pm 1$ & $\begin{array}{l}\mathrm{T}_{1} / \\
\text { Jinong28- } \\
\text { cry-3 }\end{array}$ & $18 \pm 1$ & $15 \pm 1$ & $16 \pm 2$ \\
\hline $\begin{array}{l}\text { Tol } \\
\text { Jinong28- } \\
\text { cry-4 }\end{array}$ & $17 \pm 2$ & $12 \pm 1$ & $16 \pm 2$ & $\begin{array}{l}\mathrm{T}_{1} / \\
\text { Jinong28- } \\
\text { cry-4 }\end{array}$ & $19 \pm 1$ & $17 \pm 2$ & $18 \pm 1$ \\
\hline $\begin{array}{l}\text { Tol } \\
\text { Jinong28- } \\
\text { cry-5 }\end{array}$ & $15 \pm 2$ & $10 \pm 2$ & $14 \pm 1$ & $\begin{array}{l}\mathrm{T}_{1} / \\
\text { Jinong28- } \\
\text { cry-5 }\end{array}$ & $17 \pm 2$ & $15 \pm 2$ & $17 \pm 1$ \\
\hline $\begin{array}{l}\text { Tol } \\
\text { Jinong28- } \\
\text { cry-6 }\end{array}$ & $8 \pm 2$ & $5 \pm 2$ & $6 \pm 1$ & $\begin{array}{l}\mathrm{T}_{1} / \\
\text { Jinong28- } \\
\text { cry-6 }\end{array}$ & $10 \pm 2$ & $6 \pm 1$ & $8 \pm 2$ \\
\hline $\begin{array}{l}\text { Tol } \\
\text { Jinong28- } \\
\text { cry-7 }\end{array}$ & $11 \pm 1$ & $7 \pm 2$ & $9 \pm 3$ & $\begin{array}{l}\mathrm{T}_{1} / \\
\text { Jinong28- } \\
\text { cry-7 }\end{array}$ & $12 \pm 2$ & $9 \pm 2$ & $10 \pm 2$ \\
\hline $\begin{array}{l}\text { To/ } \\
\text { Jinong28- } \\
\text { cry-8 }\end{array}$ & $6 \pm 2$ & $5 \pm 1$ & $5 \pm 1$ & $\begin{array}{l}\mathrm{T}_{1} / \\
\text { Jinong28- } \\
\text { cry-8 }\end{array}$ & $8 \pm 1$ & $5 \pm 2$ & $6 \pm 1$ \\
\hline
\end{tabular}

Note: Expression of Bt toxin in $T_{0} / T_{1}$ transgenic plants by ELISA in leaves, stems and roots. Results are means \pm SE

stress on the growth of the transgenic plants. After 2 days of $H$. parallela larval feeding on $\mathrm{V}_{2}$-stage plants, the leaves of the non-transgenic controls started to wilt, whereas the cry8-like transgenic soybean lines continued to grow well. After 4 days of feeding, the leaves of the controls were dry, yellow, and dead, whereas most leaves of the transgenic soybean plants remained green for 1 week. After 2 weeks of third-instar $H$. parallela feeding, all non-transgenic control plants had been eaten by the larvae, and the eight cry8-like transgenic lines displayed enhanced tolerance to $H$. parallela (Fig. 5c). We detected higher seedling survival rates on the transgenic plants than on the non-transgenic controls subjected to larval feeding. The survival rate of the non-transgenic controls was $92 \%$ lower than the survival rate of the eight transgenic lines (Fig. 5d). These results further demonstrated that, compared with the controls the cry 8 like transgenic lines displayed increased tolerance to $H$. parallela.

\section{Insect bioassays}

After $H$. parallela fed on leaves or roots of the eight transgenic plants for 8 days, the relative growth rate (RGR), relative consumption rate (RCR), and survival rate were determined. The RGR (Fig. 6a) and the RCR (Fig. 6b) of the larvae feeding on the roots of the eight

Table 2 Test results of between-subject effects

\begin{tabular}{llllll}
\hline Source & Type III Sum of Squares & df & Mean Square & F & Sig. \\
\hline corrected Model & $1355.259 a$ & 26 & 52.125 & 16.855 & 1817.97 \\
Intercept & 5622.241 & 1 & 5622.341 & 10.784 & 0.000 \\
Organs & 66.704 & 2 & 33.252 & 159.241 & 0.000 \\
lines & 1273.295 & 8 & 1.194 & 1.282 & 0.000 \\
Organs*lines & 14.672 & 16 & 3.093 & 0.003 \\
Error & 83.576 & 27 & & \\
Total & 7061 & 54 & & &
\end{tabular}




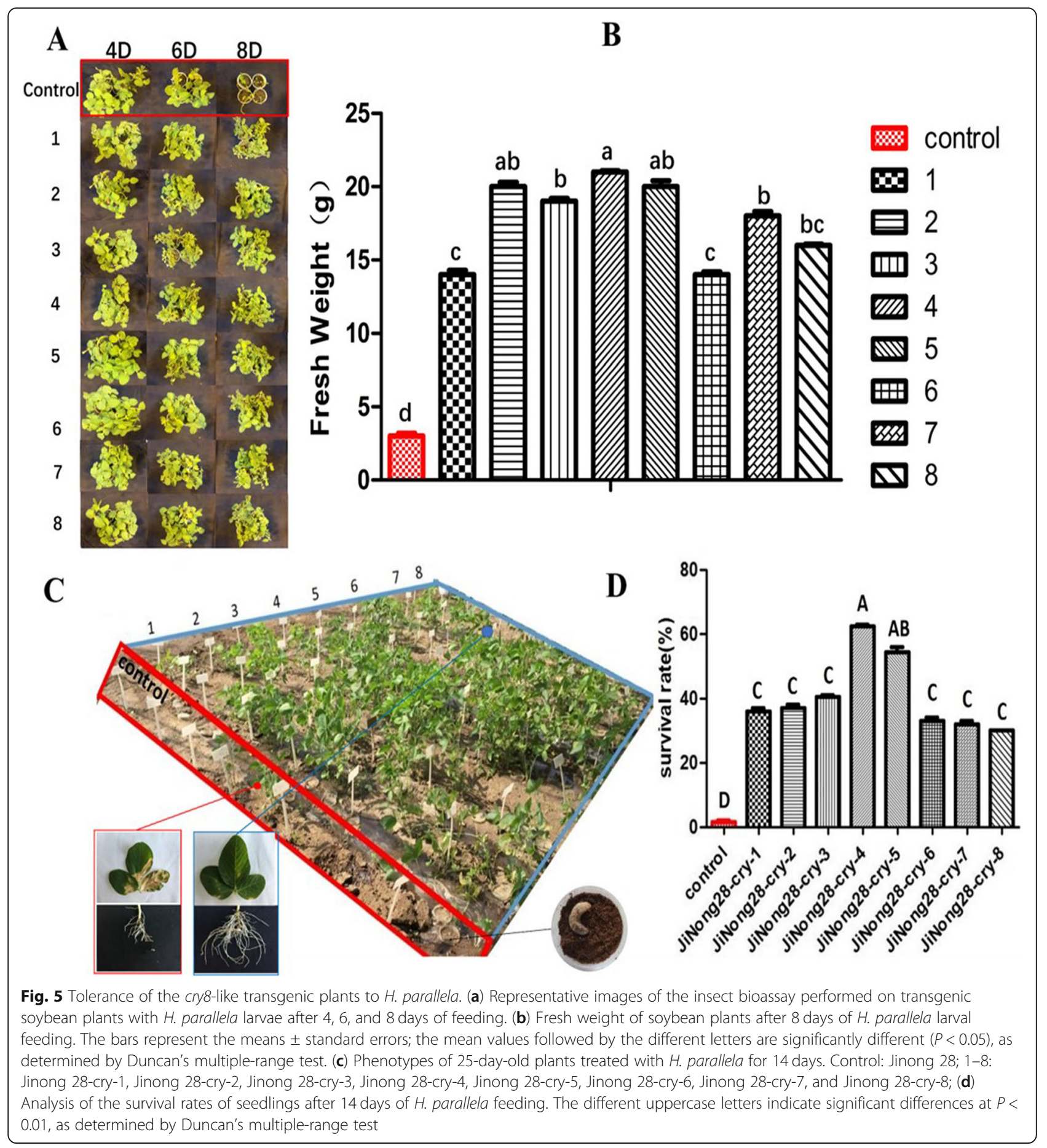

independent cry8-like transgenic lines were significantly lower than those feeding on the roots of the nontransgenic controls. The survival rates of the larvae consuming the roots of the transgenic lines declined, whereas the survival rates of the larvae consuming the roots of the non-transgenic controls were significantly higher (100\% survival) (Fig. 6c). The RGR, RCR and survival rate of $H$. parallela adults feeding on the leaves were also investigated, the RGR and RCR values of the $H$. parallela adults from the cry8-like transgenic soybean treatments were significantly lower than those of $H$. parallela adults consuming non-transgenic leaves (Fig. 6d and e, respectively). A significant difference in the survival rate of $H$. parallela adults between the cry8-like transgenic lines and the non-transgenic Jinong 28 controls was found (Fig. 6f). After H. parallela larvae fed on 


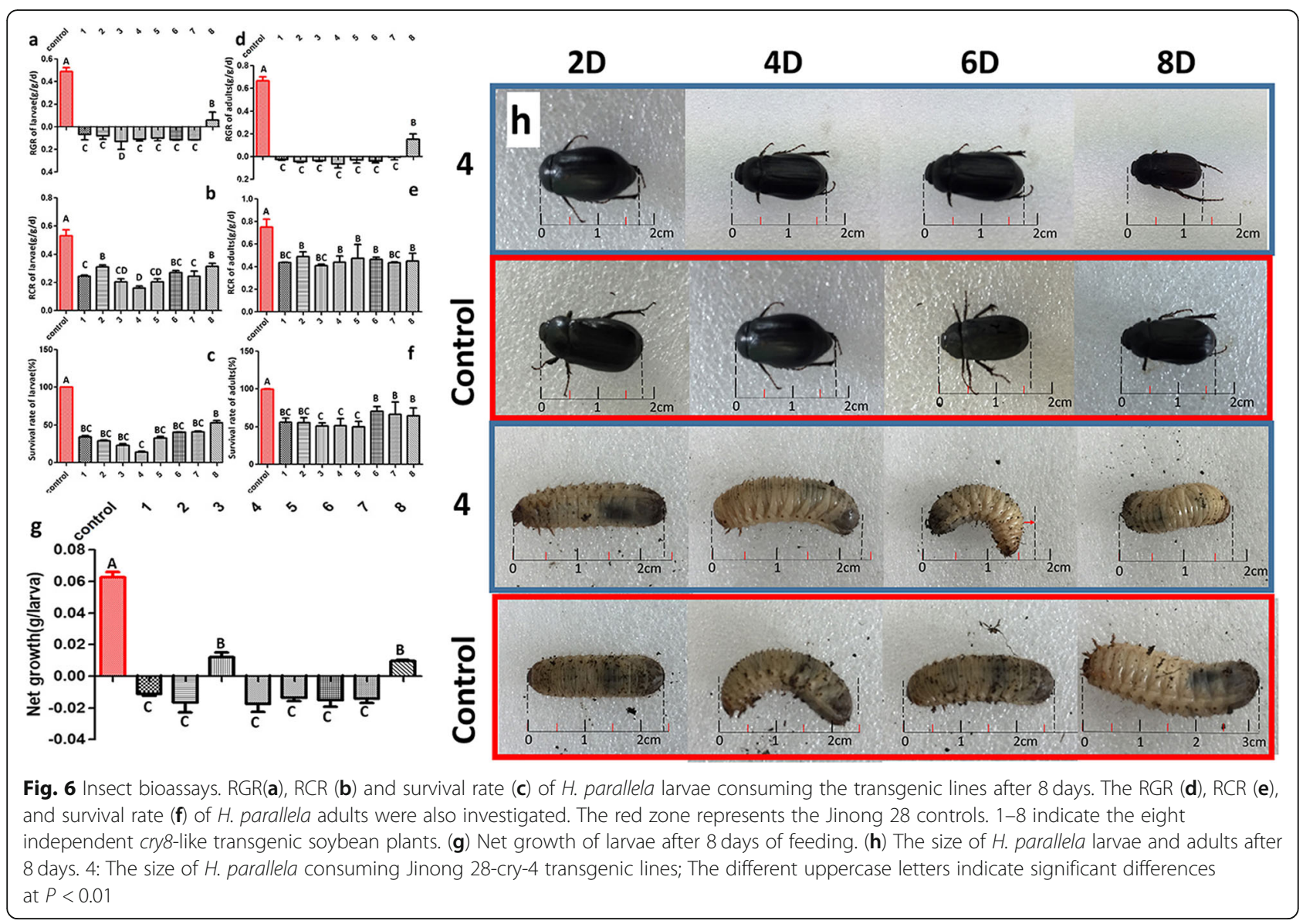

the roots of the transgenic lines for 8 days, the net growth rate of the larvae decreased from 0.017 to $0.018 \mathrm{~g} / \mathrm{larvae}$ (Fig. $6 \mathrm{~g}$ ), and the size of larvae decreased. However, compared with the larvae consuming the transgenic plants, the larvae consuming the nontransgenic controls had significantly higher net growth (0.06 g/larvae) (Fig. 6g), and their size also increased (Fig. 6h). Compared with that reared on the nontransgenic controls, the size of adult $H$. parallela insects reared on the transgenic plants expressing the cry8-like gene decreased (Fig. $6 \mathrm{~h}$ ).

\section{Agronomic performance of cry8-like transgenic lines in the field}

The agronomic characteristics such as pods per plant, seeds per plant, hundred-seed weight (HSW), seed weight per plant (SWPP), plant height and plot yield of the $\mathrm{T}_{2}$ cry8-like transgenic soybean plants grown in the field were compared with those of the non-transgenic plants grown in the field. The seeds of both transgenic and control plants presented $100 \%$ germination under normal growth conditions. The growth and fertility of the transgenic plants were compared with those of the control plants. All eight independent transgenic plants showed an exhibited phenotype and were fertile (Table 3). One-way ANOVA was used to test for significant differences among the different lines. Significant differences $(P<0.01)$ were detected in the growth and fertility status of the transgenic plants compared with the control plants. The average height of the eight transgenic lines under $H$. parallela stress was twice that of the nontransgenic Jinong 28 controls. The yield of the eight transgenic lines was significantly higher (4 times) than that of the non-transgenic controls, and the seed number per plant was four times that of the Jinong 28 controls.

\section{Discussion}

Insect pests are a major limitation to soybean production [12]. H. parallela is a beetle belonging to the Scarabaeoidea (subfamily Melolonthidae) and causes considerable damage in soybean production worldwide [13]. H. parallela larvae are difficult to control with chemical insecticides because the larvae reside in the soil.

Cry toxins (such as cry1F, cry $2 A$ and cry 8 ) have been widely used in genetically modified organisms for pest control because the toxic effects are based on the 
Table 3 Yield of cry8-like transgenic soybean plants in the field

\begin{tabular}{|c|c|c|c|c|c|c|}
\hline Line & $\begin{array}{l}\text { Pods per } \\
\text { plant }\end{array}$ & $\begin{array}{l}\text { Seed number per } \\
\text { plant }\end{array}$ & $\begin{array}{l}\text { hundred-seed weight } \\
\text { (g) }\end{array}$ & $\begin{array}{l}\text { seed weight per plant } \\
\text { (g) }\end{array}$ & $\begin{array}{l}\text { Average plant height } \\
(\mathrm{cm})\end{array}$ & $\begin{array}{l}\text { Plot yield } \\
\text { (g) }\end{array}$ \\
\hline Jinong28 & $30 \mathrm{~A}$ & $100 \mathrm{~A}$ & $10.91 \mathrm{~A}$ & $16.4 \mathrm{~A}$ & $40.292 \mathrm{~A}$ & $324.84 \mathrm{~A}$ \\
\hline $\begin{array}{l}\text { Jinong28-cry- } \\
1\end{array}$ & $78 B$ & $222 B$ & $19.71 \mathrm{~B}$ & $35.4 \mathrm{~B}$ & $106.021 \mathrm{~B}$ & $1319.80 B$ \\
\hline $\begin{array}{l}\text { Jinong28-cry- } \\
2\end{array}$ & $70 B$ & $204 B$ & $19.43 B$ & $34.9 B$ & 106.893B & 1307.28B \\
\hline $\begin{array}{l}\text { Jinong28-cry- } \\
3\end{array}$ & $72 B$ & $188 \mathrm{~B}$ & $19.82 \mathrm{~B}$ & $34.0 \mathrm{~B}$ & 102.397B & $1364.52 B$ \\
\hline $\begin{array}{l}\text { Jinong28-cry- } \\
4\end{array}$ & $70 B$ & $235 B$ & $19.29 B$ & $38.2 B$ & $105.899 \mathrm{~B}$ & $1342.20 \mathrm{~B}$ \\
\hline $\begin{array}{l}\text { Jinong28-cry- } \\
5\end{array}$ & $71 \mathrm{~B}$ & $215 B$ & $19.459 \mathrm{~B}$ & $32.5 B$ & 101.180B & $1314.4 \mathrm{~B}$ \\
\hline $\begin{array}{l}\text { Jinong28-cry- } \\
6\end{array}$ & $69 B$ & $210 B$ & $28.79 B$ & $32.5 B$ & $104.010 \mathrm{~B}$ & 1322.24B \\
\hline $\begin{array}{l}\text { Jinong28-cry- } \\
7\end{array}$ & $70 B$ & $218 B$ & $20.51 B$ & $32.2 B$ & $100.887 \mathrm{~B}$ & $1375.24 \mathrm{~B}$ \\
\hline $\begin{array}{l}\text { Jinong28-cry- } \\
8\end{array}$ & $68 B$ & $200 B$ & $21.43 B$ & $32.6 \mathrm{~B}$ & 104.897B & $1326.24 \mathrm{~B}$ \\
\hline$F$ values & 80.534 & 8.483 & 6.413 & 5.312 & 250.451 & 253.187 \\
\hline$P$ values & 0.000 & 0.002 & 0.006 & 0.005 & 0.000 & 0.000 \\
\hline
\end{tabular}

Note: Different upper letters indicate significant differences at $(P<0.01)$

disruption of midgut cells within insect pests [14, 15]. Transgenic soybeans that carry multiple $B t$ genes that provide resistance to important insect pests in agricultural crops have been produced [16, 17]. Numerous studies have indicated that $\mathrm{Bt}$ proteins can suppress major pests thus reducing insecticide use $[18,19]$. In 1994, a paper described the engineering of cry gene into soybean plants and compared the insecticidal activity of soybean plants [20]. In 2000, A transgenic lineage of the soybean 'Jack' expressing a synthetic cry1Ac gene (JackBt) was evaluated for resistance to lepidopteran pests, compared with untransformed soybean, Jack-Bt showed three to five times less defoliation from corn earworm [21]. In 2013, a study showed that the Cry1Ac-expressing $B t$ soybean provided good protection against Helicoverpa armigera, while, limited resistance was also found for transgenic soybean against pest [22]. Most studies of $B t$ transgenic soybean have shown promising insecticidal activity against lepidopteran pests, not against Scarabaeidae pest [22]. The Bt strain HBF-18 (CGMCC2070), which carries two novel cry genes (cry8-like and cry8Ga) [23], has previously been reported to exhibit toxicity to H. parallela [24]. Compared with cry8Ga, Cry8-like exhibits 3-fold greater toxicity [23], confirming that cry8like would be the best choice for expression in transgenic soybeans. These findings suggest that the insertion of an exogenous cry8-like gene into soybean is a feasible approach to produce insect resistance.

In this study, we successfully inserted the cry8-like gene into soybean to confer resistance against $H$. parallela to transgenic plants. We obtained eight independent transgenic soybean lines, each containing a single copy of the cry8-like gene. In the case of soybean, leaves and roots are the major plant parts damaged by $H$. parallela. Therefore, a high level of expression of $\mathrm{Bt}$ protein in soybean leaves and roots is important to obtain effective pest control. The present ELISA results showed that the Cry8-like levels in the two $B t$ soybean lines were relatively high, ranging from 16 to $19 \mathrm{ng} \cdot \mathrm{mg}^{-}$ ${ }^{1}$. Although levels did not reach those previously reported [25], by comparison with untransformed Jinong28, the transgenic lines showed five times greater resistance than Jinong28 to artificially infestations of $H$. parallela. In conventional field plots at one location in 2018, transgenic soybean plants also showed four times greater resistance than untransformed Jinong28 to natural infestations of $H$. parallela. According to Walker et al. [21], a transgenic line Jack-Bt also showed four times greater resistance than untransformed Jack to natural infestations of lesser cornstalk borer. The results of the bioassay revealed a significant difference in the survival of $H$. parallela reared on the eight independent transgenic soybean lines. The survival rate of $H$. parallela consuming the Jinong 28-cry-4 transgenic line was the lowest (14\%), while, the survival rate of $H$. parallela consuming the Jinong 28-cry- 8 transgenic line was the highest (57\%). Accordingly, the Jinong 28-cry-4 transgenic line had the highest accumulation of Bt protein, and the Jinong 28-cry-8 transgenic line had the lowest accumulation of Bt protein. These results suggest that 
the efficacy of insect protection was based on the level of protein accumulation in the transgenic plants. The variable insect mortality levels was mostly in agreement with the protein expression levels in the transgenic plants, and the protein expression levels in the transgenic plants was related to the intensity of expression of the cry8-like gene. The variation in transgene expression has been attributed to several factors, including differences with respect to chromosome location, copy number, and transgene construct fidelity. We investigated the transcriptional expression of the cry8-like gene in the eight independent transgenic soybean lines. All transgenic plants showed variable levels of cry8-like expression. The cry 8 -like construct was probably inserted at different locations in the plant genome, thus producing differences in Cry toxin concentration, as previously suggested in [22].

Both the cumulative and relative food consumption rates of the $H$. parallela larvae and adults feeding on the transgenic soybean plants were significantly reduced compared to those of the larvae feeding on the control plants. The mortality of $H$. parallela larvae mostly reached $100 \%$ after 2 weeks of feeding, and that of adults was $85 \%$. The results showed that the transgenic plants exerted differential effects on the larvae and adults and that the larvae seemed to be more sensitive to the $\mathrm{Bt}$ toxin than the adults. Some researchers also reported that the first and second instar are the most sensitive to Cry protein [26]. The high toxicity of Cry8-like to $H$. parallela larvae can be related to the natural tolerance of insects to the Bt proteins.

The evolution of insect resistance directly threatens $\mathrm{Bt}$ toxins efficacy in the transgenic plants [27]. The transgenic soybean plants expressing a Cry1Ac gene that showed a poor control of Spodoptera species is one example [28], as well as the western corn rootworm showing resistance to $C r y 3 B b 1$ maize in the USA [29]. Therefore, the transgenic crops including two or more Bt toxins, and novel Bt toxins are considered better options [30]. In our experiment, the novel cry8-type gene was used in the transgenic soybeans for the control of Scarabaeidae beetles. In general, our results showed that transgenic soybean plants expressing the cry8-like gene are resistant to $H$. parallela, but a limitation of the study is that only one cry gene was used. Therefore, as already suggested in [22], future research should focus on the multiple-gene $\mathrm{Bt}$ transgenic soybeans to delay the fast development of resistance in the pest.

\section{Conclusions}

In summary, our study demonstrated that cry8-like expression is an effective technique for improving resistance to $H$. parallela in soybean. The eight lines developed in this study showed enhanced resistance to
$H$. parallela adults and larvae. In addition, these lines did not have any negative impact on the agronomic traits studied.

\section{Methods \\ Biological materials}

The 1971-bp cDNA of the cry8-like gene from the Bacillus thuringiensis strain HBF-18 (from the Jilin Academy of Agricultural Sciences) was ligated into the BamHISacI site of pCAMBIA3300 [31] to place the coding region under the regulatory control of the $35 \mathrm{~S}$ promoter and the Nos terminator. The recombinant plasmid was named pCAMBIA3300-cry8-like and introduced into Agrobacterium tumefaciens strain LBA4404 via the freeze-thaw method [32]. We introduced cry8-like from the $B t$ strain HBF-18 (from the Jilin Academy of Agricultural Sciences) into the soybean cultivar Jinong 28 (Approval number 2011010), the seeds of Jinong 28 were provided by the Biotechnology Center of Jilin Agricultural University. Jinong 28 has good agronomic characteristics but no resistance to $H$. parallela. We used Agrobacterium-mediated transformation [33] to transform callus of the soybean cultivar Jinong 28 . The transformation process was divided into five sequential steps: bacterial inoculation, cocultivation, resting, selection and plant regeneration. Eight independent transgenic lines were harvested and propagated in the greenhouse: Jinong 28-cry-1, Jinong 28-cry-2, Jinong 28-cry-3, Jinong 28-cry-4, Jinong 28-cry-5, Jinong 28-cry-6, Jinong 28cry-7, and Jinong 28-cry-8. These transformed plants were used as sources of plant materials. Untransformed plants of cultivar Jinong 28 were used as controls. $\mathrm{T}_{0}$ seeds from the primary transformants were harvested and analyzed for the identification of transformants.

\section{Polymerase chain reaction analysis}

Genomic DNA from $\mathrm{T}_{0}$ and $\mathrm{T}_{1}$ plants and from the controls was extracted from the leaf tissues following the method of Kim and Hamada [34]. Quantification of DNA was performed using a Nanodrop spectrophotometer (Thermo Fisher Scientific, Waltham, Masachusetts, USA). The genomic DNA from the $T_{0}$ and $T_{1}$ transgenic plants was used to perform PCR to detect the presence of the cry8-like gene. The specific primers for PCR were designed based on the highly conserved sequence of the cry8-like gene via Primer 5.0 software (Additional file 4: Table S3). The PCR conditions were as follows: $94^{\circ} \mathrm{C}$ for $5 \mathrm{~min} ; 40$ cycles of $95^{\circ} \mathrm{C}$ for $30 \mathrm{~s}, 58^{\circ} \mathrm{C}$ for $30 \mathrm{~s}$, and $72{ }^{\circ} \mathrm{C}$ for $30 \mathrm{~s}$; and a final extension of $72^{\circ} \mathrm{C}$ for $10 \mathrm{~min}$. Genomic DNA from Jinong 28 was used as a negative control, and the vector was used as a positive control. The PCR products were subsequently analyzed by agarose gel electrophoresis. 


\section{Quantitative reverse transcription-PCR}

qRT-PCR analysis was performed to determine the transcript abundance of cry8-like. The gene-specific primer pairs P3 (5'-TTTGGATCCAAGCTTTCTAGACCCGG GCCTAT-3') and P4 (5'-TTTGAGCTCTCAAAGTTC ATCCTTCTCGGAGT-3') were used to amplify cry8like. A lectin gene (GenBank: A5547-127) was used as a reference gene, which was amplified with the primer pairs P5 (5'-GCACTTAAGATACTCTAGGTAC-3') and P6 (5'-CCACCTCCCTACTATCCATT-3'). At the three-leaf stage $\left(\mathrm{V}_{3}\right), 0.3 \mathrm{~g}$ of leaves, $0.3 \mathrm{~g}$ of stems and $0.3 \mathrm{~g}$ of roots from each plant were washed thoroughly with $\mathrm{ddH}_{2} \mathrm{O}$, and then immediately frozen in liquid nitrogen for qRT-PCR analysis. Total RNA was extracted using an RNA isolation kit (Omega Bio-tek, Norcross, GA, USA). cDNA synthesis was then performed using a reverse transcription kit (Omega Bio-tek, Norcross, GA, USA). Three biological replicates with three technical replicates of each qRT-PCR were performed. The qRTPCR analysis was performed using a Bio-Rad CFX system (Amersham Biosciences, Little Chalfont, Buckinghamshire, UK).

\section{Southern blot analysis}

Genomic DNA was isolated from leaf tissues as described previously. Approximately $2 \mu \mathrm{g}$ of DNA was digested with $\mathrm{BamHI}$, separated on $0.8 \%$ agarose gel and then blotted to Hybond ${ }^{\mathrm{m}}-\mathrm{N}+$ nylon membrane (Amersham Biosciences, Little Chalfont, Buckinghamshire, UK). Purified cry8-like gene was used as a probe, and a DIG DNA Labeling Detection Kit (Roche Company, Basel, Swiss) was used for Southern blots according to the manufacturer's instructions.

\section{Enzyme-linked immunosorbent assay (ELISA) for the quantitative estimation of the Bt protein}

We analyzed 27 samples (three replicates of each of the 8 transgenic plants plus a control plant) for the presence of the Cry8-like protein with an enzyme-linked immunosorbent assay (ELISA). Non-transgenic soybean cultivar Jinong 28 was used as a control. We essentially followed a previously published protocol [11]. The BCA protein assay kit (CWBIO, Beijing, China) was used to estimate the total soluble protein from different tissues, the antiCry8-like antibody was prepared in a rabbit. The protein concentration was calculated according to a standard method [35]. The optical density (OD) values was measured at $450 \mathrm{~nm}$ wavelength using Micro-plate reader (Biocompare, South San Francisco, USA).

\section{Insect collecting and feeding}

The $H$. parallela insects were collected from Jilin Agricultural University, Changchun, China, located at $43^{\circ} 48^{\prime}$ $\mathrm{N}, 125^{\circ} 24^{\prime} \mathrm{E}$. The $H$. parallela larvae were collected from soybean fields in late May and reared in a glasshouse on fresh roots of non-transgenic soybean plants. The $H$. parallela beetles were maintained in a ventilated incubator with a layer of soil (18-20\% moisture) and fresh leaves as a food source. Healthy individuals were selected and starved for $24 \mathrm{~h}$ before use in bioassays.

\section{Insect bioassays}

For the bioassays, $H$. parallela adults were fed leaves from the $\mathrm{T}_{1}$ transgenic plants, which had been confirmed to be transgenic by PCR, and the larvae were fed roots. One hundred insects were released per Petri dish containing $30 \mathrm{~g}$ leaves from one independent line. Each experimental unit consisted of three Petri dishes, which represent the three replicates used for each soybean line. The plates were incubated in an acclimatized room (24$26^{\circ} \mathrm{C}$, 18-h light/6-h dark cycle). The light wavelength ranged from 480 to $780 \mathrm{~nm}$. The leaves and roots were replaced with fresh material every 3 days. Observations of the behavior, mortality, and other parameters were recorded daily for 15 days. The larval survival rate was calculated as $\mathrm{N} n / \mathrm{N}_{0} \times 100$, where $\mathrm{N} n$ is the number of larvae on day $n$ of the experiment and $\mathrm{N}_{o}$ is the number of $H$. parallela larvae at the beginning of the experiment. The relative consumption rate $(\mathrm{g} / \mathrm{g} / \mathrm{d})=$ weight of food eaten/(duration of feeding $(\mathrm{d}) \times$ mean weight of the larvae). The weight of food consumed $(\mathrm{g})=$ weight of diet after feeding (g)- weight of diet before feeding (g), and the relative growth rate $(\mathrm{g} / \mathrm{g} / \mathrm{d})=$ weight gain of the lar$\mathrm{vae} /($ duration of feeding $(\mathrm{d}) \times$ mean weight of the larvae).

\section{Field trial evaluations}

The cry8-like transgenic soybean plants and Jinong 28 control plants were grown at Jilin Agricultural University, Changchun, China, located at $43^{\circ} 48^{\prime} \mathrm{N}, 123^{\circ} 24^{\prime} \mathrm{E}$. A randomized complete block design was used. The field was divided into three blocks of $300 \mathrm{~m}^{2}(15 \times 20 \mathrm{~m})$, each of which was subdivided into nine subsections. Seeds were planted in nine random subsections of each block. The plants were grown under natural temperature, light and humidity conditions during the season. The climate of the region is considered semiarid, and the region is considered to be a representative region for typical soil in Northeast China. Two months after sowing, the $H$. parallela adults and third-instar larvae were released into the field $\left(100 / 300 \mathrm{~m}^{2}\right)$. Pesticides were not applied prophylactically at the seeding stage. The following characteristics were measured: plant height, pods per plant, seed number per plant, grain yield and hundred-seed weight. The pods of each plant were counted for 100 plants per line, and the average number was calculated. The hundred-seed weight was determined from 100 randomly chosen soybean samples, and the yield was obtained by weighing the grain mass. 


\section{Data analysis}

All data were analyzed via SPSS version 22.0 software (SPSS Inc., Chicago, IL, USA) [36], each with three replicates. Two-way ANOVA was used to test whether the soybean lines or organs had a significant effect on the accumulation of the Cry8-like protein and the cry8-like gene in the transgenic lines. These analyses of variance were performed in two steps. Two-way ANOVAs (including all interactions and simple and main effects) were used to test for significant differences among the transgenic lines. The means were subsequently tested a posteriori to the ANOVAs via Duncan's test at the 0.05 probability level. One-way ANOVA in conjunction with Student's $t$ test was used to determine whether the differences in the agronomic characteristics between the eight different transgenic lines were significant. $P<0.01$ was considered statistically significant.

\section{Supplementary information}

Supplementary information accompanies this paper at https://doi.org/10. 1186/s12896-019-0563-1.

Additional file 1: Fig. S1. Detection of the different cry8-like transgene regions in the eight transgenic lines by PCR.

Additional file 2: Table S1. Significant differences among transgenic soybean lines.

Additional file 3: Table S2. Significant differences among plant organs. Additional file 4: Table S3. Primers used for the experiments in this study.

\section{Abbreviations}

d: Day; ELISA: Enzyme-linked immunosorbent assay; H: Hour; HSW: Hundredseed weight; qRT-PCR: Quantitative reverse transcription-polymerase chain reaction; RCR: Relative consumption rate; $R G R$ : Relative growth rate: SWPP: Seed weight per plant

\section{Acknowledgements}

We are grateful for the generous grant from the Biotechnology Center of Jilin Agricultural University and the Jilin Academy of Agricultural Sciences that made this work possible.

\section{Authors' contributions}

WP and QD designed the experiments. QD, XL and ZQ planned and performed the experiments. CM and QD edited the manuscript. All authors discussed the results and commented on the manuscript. All authors have read and approved the manuscript.

\section{Funding}

The project was funded by National Genetically Modified New Varieties of Major Projects of China (2016X8004-004). The funding bodies had no role in the design of the study and collection, analysis, and interpretation of data and in writing the manuscript.

\section{Availability of data and materials}

All the data or materials used during this study are available from the corresponding author upon reasonable request.

Ethics approval and consent to participate

Not applicable.

\section{Consent for publication}

Not applicable.

\section{Competing interests}

The authors declare that they have no competing interests.

\section{Author details}

${ }^{1}$ Biotechnology Center of Jilin Agricultural University, Jilin Agricultural University, Changchun 130118, People's Republic of China. ${ }^{2}$ School of Biosciences and Veterinary Medicine, University of Camerino, MC, Camerino, Italy. ${ }^{3}$ College of Life Sciences, Kyung Hee University, 1732, Deogyeong daero, Giheung-gu, Yongin-si, Gyeonggi-do 17104, Republic of Korea.

Received: 24 February 2019 Accepted: 26 September 2019

Published online: 15 October 2019

\section{References}

1. Hill AM, Katcher HI, Flickinger BD, Kris-Etherton PM. Human nutrition value of soybean oil and soy protein. Champaign, Illinois: AOCS Press; 2008.

2. Wang C-L. Soybean insects occurring at podding stage in Taichung. J Agric Res China. 1980;29:283-6.

3. Shi S, Cui J, Song P, Zang D, Li W, Wu T. Occurring regularity of Holotrichia parallela in summer soybean field. Soybean Sci. 2014;33:91-4.

4. Bravo A, Gómez I, Porta H, García-Gómez Bl, Rodriguez-Almazan C, Pardo L, et al. Evolution of Bacillus thuringiensis cry toxins insecticidal activity. Microb Biotechnol. 2013;6:17-26.

5. Kumar S, Chandra A, Pandey KC. Bacillus thuringiensis (Bt) transgenic crop: an environment friendly insect-pest management strategy. J Environ Biol. 2008;29:641-53.

6. Ostlie K, Hutchison WD, Hellmich R. Bt corn and European corn borer. University of Nebraska: Lincoln; 1997.

7. Xue J, Liang GM, Crickmore N, Li H, He K, Song FP, et al. Cloning and characterization of a novel cry1A toxin from Bacillus thuringiensis with high toxicity to the Asian corn borer and other lepidopteran insects. FEMS Microbiol Lett. 2008;280:95-101.

8. Burlet A, Chapleur-Chateau M, Haumont-Pellegri B, Jansen F, Menzaghi F, Fernette $B$, et al. Characterization of cry genes in a Mexican Bacillus thuringiensis strain collection. Appl Environ Microbiol. 1998;64:4965.

9. Anilkumar KJ, Rodrigo-Simon A, Ferre J, Pusztai-Carey M, Sivasupramaniam S, Moar WJ. Production and characterization of Bacillus thuringiensis cry1Acresistant cotton bollworm Helicoverpa zea (Boddie). Appl Environ Microbiol. 2008:74:462-9.

10. Shu C, Yan G, Wang R, Zhang J, Feng S, Huang D, et al. Characterization of a novel cry8 gene specific to Melolonthidae pests: Holotrichia oblita and Holotrichia parallela. Appl Microbiol Biotechnol. 2009;84:701-7.

11. Geng L, Chi J, Shu C, Gresshoff PM, Song F, Huang D, et al. A chimeric cry8Ea1 gene flanked by MARs efficiently controls Holotrichia parallela. Plant Cell Rep. 2013;32:1211-8.

12. Rupe J, Luttrell RG. Effect of pests and diseases on soybean quality. In: Johnson LA, White PJ, Galloway R, editors. Soybeans: chemistry, production processing, and utilization. Champaign, Illinois: AOCS Press; 2008. p. 93-116.

13. Kogan M, Irwin M, Sinclair J, Slife F. Major world soybean diseases, weeds and insect pests: a diagnostic pictorial atlas. Urbana, Illinois: National Soybean Research Laboratory; 1997

14. Bandyopadhyay D. Genetically modified crops, agriculture and biosafety. In: Securing our natural wealth. Singapore: Springer; 2018. p. 81-91.

15. Romeis J, Meissle M, Bigler F. Transgenic crops expressing Bacillus thuringiensis toxins and biological control. Nat Biotechnol. 2006;24:63-71.

16. Roh JY, Choi JY, Li MS, Jin BR, Je YH. Bacillus thuringiensis as a specific, safe, and effective tool for insect pest control. J Microbiol Biotechnol. 2007;17: 547-59.

17. Datta K, Vasquez A, Tu J, Torrizo L, Alam MF, Oliva N, et al. Constitutive and tissue-specific differential expression of the $c r y / A(b)$ gene in transgenic rice plants conferring resistance to rice insect pest. Theor Appl Genet. 1998;97: 20-30.

18. Lu Y, Wu K, Jiang Y, Guo Y, Desneux N. Widespread adoption of Bt cotton and insecticide decrease promotes biocontrol services. Nature. 2012;487: 362-5.

19. Bravo A, Likitvivatanavong S, Gill SS, Soberon M. Bacillus thuringiensis: a story of a successful bioinsecticide. Insect Biochem Mol Biol. 2011;41:423-31.

20. Parrott WA, All JN, Adang MJ, et al. Recovery and evaluation of soybean plants transgenic for a Bacillus thuringiensis var. Kurstaki insecticidal gene. In Vitro Cell Dev Biol Plant. 1994;30(3):144-9. 
21. Walker DR, All JN, McPherson RM, et al. Field evaluation of soybean engineered with a synthetic cry 7 Ac transgene for resistance to corn earworm, soybean looper, velvetbean caterpillar (Lepidoptera: Noctuidae), and lesser cornstalk borer (Lepidoptera: Pyralidae). J Econ Entomol. 2000; 93(3):613-22.

22. $Y u H$, Li Y, Li X, et al. Expression of Cry $1 A c$ in transgenic Bt soybean lines and their efficiency in controlling lepidopteran pests. Pest Manag Sci. 2013; 69(12):1326-33.

23. Jiang J, Huang Y, Shu C, Soberon M, Bravo A, Liu C, et al. Holotrichia oblita midgut proteins that bind to Bacillus thuringiensis cry8-like toxin and assembly of the $\mathrm{H}$. oblita midgut tissue transcriptome. Appl Environ Microbiol. 2017;83:e00541-17.

24. Bi Y, Zhang Y, Shu C, Crickmore N, Wang Q, Du L, et al. Genomic sequencing identifies novel Bacillus thuringiensis Vip1/Nip2 binary and cry8 toxins that have high toxicity to Scarabaeoidea larvae. Appl Microbiol Biotechnol. 2015;99:753-60.

25. Macrae TC, Baur ME, Boethel DJ, et al. Laboratory and field evaluations of transgenic soybean exhibiting high-dose expression of a synthetic Bacillus thuringiensis cry $7 \mathrm{~A}$ gene for control of Lepidoptera. J Econ Entomol. 2005; 98(2):577-87.

26. Shanmugam PS, Balagurunathan R, Sathiah N. Susceptibility of Helicoverpa armigera Hübner instars to Bacillus thuringiensis insecticidal crystal proteins. Pestic Res J. 2006;18(2):186-9.

27. Soberón M, Pardo-López L, López I, et al. Engineering modified Bt toxins to counter insect resistance. Science. 2007;318(5856):1640-2.

28. Bernardi O, Sorgatto RJ, Barbosa AD, et al. Low susceptibility of Spodoptera cosmioides, Spodoptera eridania and Spodoptera frugiperda (Lepidoptera: Noctuidae) to genetically-modified soybean expressing Cry 1 Ac protein. Crop Prot. 2014;58:33-40.

29. Gassmann AJ, Petzold-Maxwell JL, Keweshan RS, et al. Field-evolved resistance to Bt maize by western corn rootworm. PLoS One. 2011;6(7): e22629.

30. Sheikh AA, Wani MA, Bano P, et al. An overview on resistance of insect pests against Bt crops. J Entomol Zool Stud. 2017;5:941-8.

31. Wu N, Wang P, Lin N, Lu S, Feng Y, Rong J, et al. Construction of a chalcone reductase expression vector and transformation of soybean plants. Mol Med Rep. 2017;16:6178-83.

32. Wang X-Q, Shen X, He Y-M, Ren T-N, Wu W-T, Xi T. An optimized freezethaw method for transformation of Agrobacterium tumefaciens EHA 105 and LBA 4404. Pharm Biotechnol. 2011;18:382-6.

33. Donaldson PA, Simmonds DH. Susceptibility to Agrobacterium tumefaciens and cotyledonary node transformation in short-season soybean. Plant Cell Rep. 2000;19:478-84.

34. Kim SH, Hamada T. Rapid and reliable method of extracting DNA and RNA from sweetpotato, Ipomoea batatas (L). Lam Biotechnol Lett. 2005;27:1841-5.

35. Palmer HM. Using antibodies: a laboratory manual. J Antimicrob Chemother. 2000;45:413.

36. Verma JP. Data analysis in management with SPSS software. Springer Science \& Business Media: Berlin, Germany; 2013.

\section{Publisher's Note}

Springer Nature remains neutral with regard to jurisdictional claims in published maps and institutional affiliations.

Ready to submit your research? Choose BMC and benefit from:

- fast, convenient online submission

- thorough peer review by experienced researchers in your field

- rapid publication on acceptance

- support for research data, including large and complex data types

- gold Open Access which fosters wider collaboration and increased citations

- maximum visibility for your research: over $100 \mathrm{M}$ website views per year

At $\mathrm{BMC}$, research is always in progress.

Learn more biomedcentral.com/submissions 